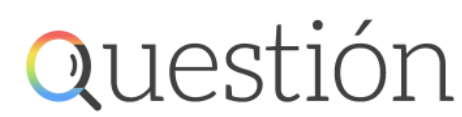

Periodismo / Comunicación ISSN 1669-6581
- Av. $44 \mathrm{~N}^{\circ} 676,1^{\circ}$ piso

CP 1900 - La Plata - Argentina

www.perio.unlp.edu.ar/question

Realidad del Covid-19 en Panamá

Reisa Mirella Vega Ríos

https://doi.org/10.24215/16696581e394

\title{
Realidad del COVID-19 en Panamá
}

\author{
Reality of COVID-19 in Panama
}

Reisa Mirella Vega Ríos.

Panameña. Tiene 20 años de docencia en la Universidad Autónoma de Chiriquí en la Facultad de Comunicación Social, Escuela de Periodismo. Vicedecana 2014-2019 de la Facultad. Directora de la Radio Universitaria 2011 - 2013. Posee licenciatura Periodismo, licenciatura en Política Internacional, Posgrado en Entornos Virtuales, Maestría en Comunicación Social y es Doctoranda en Docencia Superior. Ha elaborados proyectos académicos como el Diplomado de Interculturalidad y Comunicación desde la Perspectiva de los Pueblos Indígenas UNFPA -UNACHI- FCS, la creación del Centro de Investigación para la Integración e Internalización de la Tecnología de la Comunicación para el Desarrollo de la Sociedad (CIIITECODESO) y el Centro de Investigación para la Producción Audiovisual, Diseño e Imagen (CIPADI).

Actualmente es la Directora Suplente ante la Federación Latinoamericana de Facultades de Comunicación Social

(FELAFACS) por la Región Centroamericana, cargo que ejerce desde el 2016 al 2021.

Mantiene el espacio radial "Nuestras Voces" por Radio Universitaria 93.3 FM, e incursiona en una plataforma Web personal donde trabaja temas sobre internacionalización, desarrollo sostenible y ser la voz para vivir con equidad, compromiso, armonía y respeto por nuestro entorno.

\section{Palabras Clave}

Relatos - Internacional - Nueva Normalidad

\section{Key Words}

Stories - International - New Normal

Relato de la experiencia de la "Nueva Normalidad" anunciada por el gobierno de Panamá el 20 de mayo de 2020, en la provincia de Chiriquí al oeste de Panamá, que limita con Costa Rica y el océano Pacífico. La ruta Los Quetzales recorre los bosques nubosos de la región y conecta la comunidad agrícola rústica de Cerro Punta con Boquete, una base para actividades al aire libre como el excursionismo, el alpinismo y el descenso de ríos.

\section{Enlace}

https://ar.ivoox.com/es/51718285 